\title{
UTILIZAÇÃO DE VÍDEOS EDUCATIVOS DE BIOLOGIA NO YOUTUBE POR ESTUDANTES DO ENSINO MÉDIO
}

\author{
USE OF BIOLOGY EDUCATIONAL VIDEOS ON YOUTUBE \\ BY HIGH SCHOOL STUDENTS
}

\section{USO DE VIDEOS EDUCATIVOS DE BIOLOGÍA EN YOUTUBE \\ POR ESTUDIANTES DE ESCUELA SECUNDARIA}

Maria Eduarda Melo ${ }^{1}$; Leandro Duso ${ }^{2}$

\begin{abstract}
RESUMO
Os vídeos educativos do YouTube apresentam um papel cada vez mais relevante na formação dos estudantes, especialmente no estudo das Ciências Naturais. Esta pesquisa investigou a relação dos estudantes do ensino médio com os vídeos educativos de Biologia disponíveis na plataforma YouTube, quanto ao uso, à frequência, às motivações e às preferências. Para isso, realizou-se um questionário com 132 estudantes do ensino médio do Colégio de Aplicação da UFSC em Florianópolis e, posteriormente, formou-se um grupo focal com oito estudantes sorteados, para aprofundamento de algumas questões. A análise dos dados mostrou que os vídeos de Biologia da plataforma YouTube vêm sendo buscados frequentemente para o estudo dos conteúdos curriculares dessa disciplina, com o objetivo principal de tirar boas notas nos exames. Além disso, observou-se que existe um grupo de canais mais assistidos, que apresentam um modelo de aula preferido entre os estudantes, o que indica, o uso dos vídeos como um meio para repetir o processo que acontece na escola.
\end{abstract}

PALAVRAS-CHAVE: Canais educativos. Ensino por vídeo. Vídeo educativo. Biologia.

\begin{abstract}
Educational videos on YouTube seem to play an increasingly important role at students education, especially in the study of nature sciences subjects. This research investigated the relationship of high school students with biology educational videos available on the YouTube platform, regarding frequency, motivations and preferences of use. A questionnaire was applied to 132 high school students from Colégio de Aplicação of Federeal University of Santa Catarina in Florianópolis. Subsequently, a focus group was formed with eight randomly selected students for deepening. The analysis showed that Biology videos on the YouTube platform have been frequently searched for the study of the curricular contents of this discipline and the main motivation of use is to get good grades in exams. In addition, it was observed that there is a group of more watched channels, which present a preferred class model among students, these results indicate the use of videos as a means to repeat a model that already happens at school.
\end{abstract}

KEYWORDS: Educational channels. Educational technology. Educational video. Biology education.

\footnotetext{
${ }^{1}$ Mestranda - Programa de Pós-Graduação em Educação Científica e Tecnológica - Universidade Federal de Santa Catarina (PPGECT/UFSC). Florianópolis, SC - Brasil. Associada à Associação Brasileira de Pesquisa em Educação em Ciências (ABRAPEC) e Associação Brasileira de Ensino de Biologia (SBEnBio). E-mail: ddudamelo@gmail.com

${ }^{2}$ Doutor em Educação Cientifica e Tecnológica - Universidade Federal de Santa Catarina (PPGECT/UFSC). Florianóplis, SC - Brasil. Professor do magistério superior - Universidade Federal de Santa Catarina (UFSC). Florianóplis, SC - Brasil. E-mail: dusoleandro@gmail.com

Submetido em: 20/03/2021 - Aceito em: 22/11/2021
}

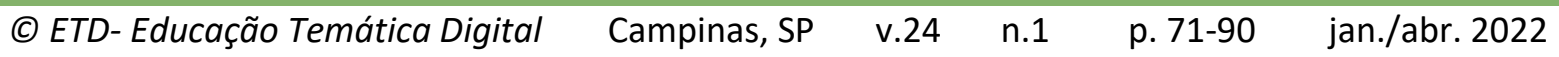


estão fazendo uso desse recurso pode possibilitar uma melhor compreensão sobre o processo educativo desses sujeitos, que acontece fora da escola, no contexto atual, bem como incitar uma reflexão paralela do próprio processo de ensinar e aprender na sala de aula.

Assim, este texto, que representa um recorte de um trabalho de conclusão de curso (AUTORA, 2018), propôs-se a investigar como os estudantes do ensino médio utilizam vídeos educativos do YouTube para acessar os conteúdos de Biologia. Para tanto, buscou-se identificar a frequência de acesso aos vídeos, os canais mais acessados e as motivações que levam os estudantes à busca por esses vídeos. Participaram da pesquisa 132 estudantes dos três anos do ensino médio do Colégio de Aplicação da Universidade Federal de Santa Catarina (CA-UFSC).

\section{PERCURSO METODOLÓGICO}

O presente trabalho caracteriza-se como uma pesquisa qualitativa (MINAYO et al., 2002), visto que investigou relações existentes entre estudantes do ensino médio e o uso de vídeos educativos do YouTube com a finalidade de estudar Biologia, e exploratória, já que proporcionou uma maior familiaridade com um tema ainda pouco investigado, tornando-o mais conhecido e explícito (GIL, 2008).

Participaram da pesquisa 132 estudantes de seis turmas do ensino médio do Colégio de Aplicação da Universidade Federal de Santa Catarina (CA-UFSC) em Florianópolis-SC, sendo duas turmas representantes de cada um dos três anos. O CA-UFSC atende estudantes de todas as regiões de Florianópolis assim como de cidades vizinhas dado que o ingresso se dá via sorteio de vagas, o que, a princípio, indica uma diversidade socioeconômica de estudantes. Considerada uma escola modelo, o CA-UFSC possui mais de 940 estudantes matriculados em mais de 38 turmas distribuídas nas modalidades de ensino fundamental e médio. Isto posto, a coleta de dados foi realizada com base em dois instrumentos: primeiramente, a partir de um questionário e, posteriormente, com a construção de um grupo focal que seguiu um roteiro pré-elaborado. O roteiro do grupo focal foi desenvolvido inspirado nas categorias de discussão propostas na pesquisa de Silva, Pereira e Arroio (2017).

O questionário foi elaborado tendo em vista as recomendações técnicas indicadas por Gil (2008). As sete questões objetivas envolveram a frequência com que os estudantes assistiam a vídeos de Biologia no YouTube, a motivação que leva à busca, os canais mais assistidos e os conteúdos de Biologia mais procurados. Assim, o questionário pretendia esclarecer, de forma mais geral, um padrão de ação e comportamento dos estudantes participantes em sua relação com os vídeos de Biologia no YouTube.

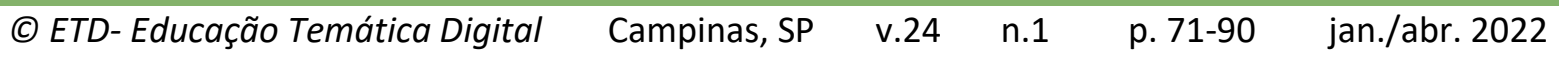


Após a aplicação do questionário, a coleta de dados teve prosseguimento com o grupo focal, visando uma complementação das informações obtidas com o primeiro instrumento e um aprofundamento de outras, a fim de trazer novos entendimentos sobre 0 objeto de estudo. A partir de um grupo focal, é possível obter diferentes perspectivas acerca de uma mesma questão, bem como perceber a linguagem de resposta, as reações coletivas, as sequências de raciocínio e outras interações entre o grupo (GATTI, 2005), que também foram alvos de observação durante o encontro. A condução do encontro do grupo focal deste trabalho foi amparada nas recomendações técnicas feitas por Gatti (2005), de forma a explorar, do melhor modo, este instrumento.

Para o grupo focal, foram sorteados dois estudantes de cada turma, que tivessem respondido integralmente ao questionário, bem como respondido "Sim" para a pergunta "Já buscou conteúdos de Biologia no YouTube?". Assim, 12 estudantes foram convidados a participar, dos quais oito, com representantes dos três anos do ensino médio, participaram efetivamente. $O$ encontro teve duração de uma hora, contou com um mediador e dois relatores, foi gravado na íntegra e possibilitou uma maior diretividade em algumas questões que deixaram lacunas no questionário.

Quanto às questões éticas do trabalho, a pesquisa foi apresentada à direção e ao corpo docente do colégio e passou por aprovação mediante documento assinado pelos mesmos, ficando registrada nas atividades da instituição. Para os estudantes, um documento de TCLE foi entregue para ser assinado (por eles ou pelos pais ou responsáveis no caso de estudantes menores de idade) a fim de permitir a participação na pesquisa. Assim, reiteramos que todos os dados publicados neste trabalho passaram por autorização prévia por parte da escola, corpo docente, estudantes e dos pais ou responsáveis legais, e apenas os estudantes que tiveram o TCLE devidamente assinado tiveram suas falas apresentadas nas discussões trazidas nesta pesquisa, sob a proteção de suas verdadeiras identidades.

Em relação à análise do questionário, as questões foram avaliadas separadamente e sistematizadas com auxilio do programa Microsoft Office Excel. Recorreu-se aos dados produzidos no questionário para complementar os dados qualitativos gerados a partir do grupo focal. Em relação ao grupo focal, o áudio foi gravado e transcrito na íntegra. Para manter a identidade dos participantes do encontro, nos relatos, cada um recebeu um sinal de identificação, representado por uma letra e um número - E1 a E8 -, bem como os relatores e o mediador, representados respectivamente por R1, R2 e M. Além disso, a expressão "Estudante não identificado pelo áudio" significa que não foi possível identificar a voz do estudante que falou. A interpretação dos dados do grupo focal foi conduzida a partir do agrupamento de respostas comuns, que gerou categorias a posteriori. Ao longo da sessão a seguir, estas são discutidas a partir do que chamou-se de eixos principais.

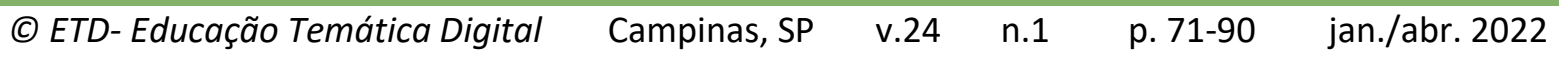


semana", 9\% assinalaram "uma vez por ano" e 4\% assinalaram "todo dia". Os dados aqui observados vão ao encontro de Silva, Pereira e Arroio (2017), que observaram que faz parte do hábito de estudo da maioria dos estudantes buscar por vídeos de Biologia no YouTube para estudar, assim como também de Física e Química.

Sobre o hábito de assistir a vídeos de Biologia no YouTube, os estudantes não gostam daqueles que apresentem informações a mais do que estão a buscar; querem alcançar a informação que lhes interessa naquele momento, de forma rápida e objetiva, trocando de vídeo quantas vezes forem necessárias para isso, afirma E4: "Por isso que eu to aqui, [...] eu quero uma coisa mais didática, às vezes mais enxugada até". Além disso, os estudantes afirmaram que o tempo dos vídeos é um critério de escolha importante e que, quanto mais curto, melhor, como afirma o E8: "Aí aqueles vídeos de uma hora eu durmo, se for tipo aí, no máximo 15 minutos explicando tá bom, daí, se passar disso, 'ixiii'".

Segundo Rezende Filho et al. (2015), a produção e disseminação dos vídeos educativos no YouTube veio acompanhada de um discurso que valoriza a objetividade e eficiência, de ser exatamente o que o estudante precisaria saber em relação a um dado conteúdo, e assim, é alterada a relação que a juventude tem com o conhecimento (SILVA; SALES, 2015) e com o tempo, pois desenvolve uma cultura própria de acesso e uso dessas informações, pautada na rapidez e na objetividade.

O aparelho eletrônico que os estudantes costumam utilizar para acessar o YouTube é o celular. De encontro a isso, Silva, Pereira e Arroio (2017) observaram que os estudantes utilizavam mais o computador como ferramenta de acesso do que o celular. Ainda, em relação ao momento e à maneira como assistem aos vídeos no YouTube, os estudantes afirmaram que, na maioria das vezes estão em casa, confortáveis e bem acomodados, mas, algumas vezes, também assistem durante o trajeto até a escola, no ônibus: "O YouTube é uma forma rápida, principalmente porque a gente vive em ônibus, então, baixou, o vídeo tá ali", afirma o E4, mostrando que o celular, como aparelho eletrônico portátil, é importante nesses momentos, pois permite o uso em diversos ambientes, como os ônibus.

Em síntese, viu-se que os estudantes têm o uso do YouTube incorporado em suas rotinas diárias, bem como em suas rotinas de estudo, visto que acessam diariamente a plataforma e buscam, com certa recorrência, o YouTube para ver conteúdos de Biologia. Quando acessam, são diretos no que pretendem assistir, mostrando que objetividade e praticidade são pontos importantes. Ainda, utilizam majoritariamente o celular como aparelho eletrônico de acesso visto que este se permite ser usado em diversos ambientes, e gostam de estar confortáveis e acessar o YouTube principalmente quando estão em casa e sozinhos. 
3.2 Motivações da busca de vídeos educativos de Biologia no YouTube

Dado o contexto de que os estudantes do ensino médio fazem uso frequente dos vídeos no YouTube para estudar conteúdos de Biologia, mostrou-se interessante entender o que os levam à buscá-los, ou seja, quais são suas motivações. Em seu tempo livre, afirmaram que buscam e navegam sobre assuntos de interesse pessoal, que variam dentre os conteúdos disponíveis, como: maquiagem, resenhas de filmes, músicas, aulas e jogos.

Além da busca guiada pelos interesses pessoais, percebeu-se que existiam outras motivações, relacionadas ao processo de ensino e aprendizagem, que levam ao uso do YouTube para acessar conteúdos de Biologia e também de outras disciplinas. Dentre as opções, 42\% dos estudantes afirmaram ser "estudar para a prova" a principal motivação de busca de vídeos de Biologia no YouTube enquanto que $29 \%$ afirmaram ser "tirar dúvidas sobre o conteúdo", que também se apresentou como uma forte motivação. A opção "estudar para o vestibular" ficou entre as motivações menos significativas, e "curiosidade pessoal" recebeu uma razoável parcela de resposta. Assim, a prova curricular é a maior motivação de busca por vídeos de Biologia no YouTube pelos estudantes, assim como apresentado por Medina, Braga e Rego (2015), que também observaram que mais de $35 \%$ dos estudantes só assistiam à aulas em vídeo na véspera da prova.

Quando indagados sobre os motivos que os levam a buscar vídeos de Biologia no YouTube, os estudantes afirmaram:

$$
\begin{aligned}
& \text { M: Quais motivos levam vocês a buscarem vídeos de Biologia no YouTube? } \\
& \text { E1: Tédio. }
\end{aligned}
$$

Estudante não identificado pelo áudio: Prova!

E2: Prova!

E4: Prova. É... quando tá com dúvida em alguma matéria, e aí não tem os conteúdos certos, "tu vai" no YouTube e pesquisa.

E3: 'Ãn'... eu pesquiso quando o professor, eu não entendi o que o professor quis dizer ou até 'pra' pesquisar um pouco mais 'pra' prova.

E5: [...] atualmente, os últimos que eu vi foi pra estudar para a prova.

Com exceção do E1, todos mencionaram o termo "prova", deixando claro o poder das provas sobre a busca de vídeos. Em duas falas, a categoria "dúvida" até aparece, porém, mostra-se muito ligada à prova, visto que as dúvidas surgem no momento do estudo para esse tipo de avaliação, e é a partir dessas que o estudante recorre ao YouTube, como dito por E3 e E4. Durante toda a conversa, a prova foi marcada como a maior preocupação letiva dos estudantes e que seus hábitos escolares giram em torno dela.

(C) ETD-Educação Temática Digital $\quad$ Campinas, SP $\quad$ v.24 $\quad$ n.1 $\quad$ p. 71-90 jan./abr. 2022


Ainda, segundo os estudantes, a busca de vídeos pela simples curiosidade sobre o conteúdo torna-se um evento raro, assim como visto por Medina, Braga e Rego (2015), em que poucas vezes ou nunca os estudantes assistiam a uma aula em vídeo com o objetivo de sanar uma curiosidade sobre algum assunto apresentado; era sempre para revisar ou aprender a matéria para uma prova.

Dado o foco nas provas, quando buscam por vídeos de Biologia, os estudantes não estão interessados em entender processos com detalhadas explicações; querem o mais prático e objetivo, que pareça ao máximo com a resposta da prova, visto que vêm de uma cultura escolar que avalia e prioriza a resolução de exercícios típicos e definições padronizadas em detrimento do desenvolvimento de diversos saberes e da crítica, o que justifica também a falta de busca de assuntos pela simples curiosidade (MEDINA; BRAGA; REGO, 2015). Dessa forma, não possuem interesse em buscar além do que precisam saber para tirar boas notas, o que reforça a ideia de um processo de aprendizagem limitado.

Portanto, quando questionados sobre os conteúdos curriculares específicos de Biologia que mais procuram no YouTube, os estudantes responderam que são os próprios conteúdos curriculares que estão aprendendo em seus anos letivos. Em consonância com os conteúdos de Biologia que estudam em cada um dos anos no CA-UFSC, os estudantes do primeiro ano buscavam mais conteúdos relacionados à Bioquímica e Citologia; os do segundo ano buscavam especialmente Botânica e Zoologia, e os do terceiro ano buscavam principalmente Genética.

Em relação a testes em uma escala um pouco maior, "estudar para o vestibular" não se apresentou como uma motivação muito significativa de uso do YouTube, com apenas $10 \%$ das respostas. Entretanto, quando questionados sobre o que pretendem fazer ao fim do ensino médio, a maioria dos estudantes relatou que almeja o ensino superior. Em vista disso, quando indagados sobre usar o YouTube para estudar para o vestibular (não necessariamente conteúdos de Biologia), relataram que o uso é comum, mas não compatível com a filosofia do colégio.

O CA-UFSC não apresenta a ideia de ensino médio como preparatório para o vestibular, assim, o colégio apresenta uma visão mais holística de formação do estudante: responsabilidade social, afirmação histórica dos educandos e expansão de sua personalidade (CA-UFSC, 2003). Dessa forma, pareceu haver insatisfação por parte de uma estudante quanto aos professores não desenvolverem mais os conteúdos para o vestibular; ela afirma que acabam tendo que buscar alternativas para isso, vendo no YouTube um espaço para estudar para esse tipo de teste. Rezende Filho et al. (2015), numa pesquisa que incluiu 36 canais de vídeos de Ciências no YouTube, observaram que 19 canais eram

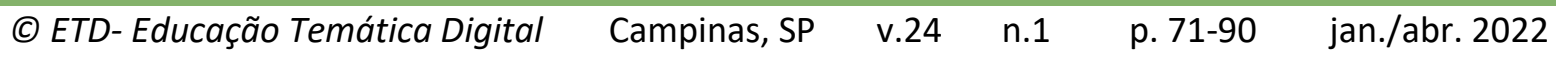


especificidade (25) na escolha do canal. Destaca-se a variedade surpreendente que alguns estudantes trouxeram, sendo contabilizados sete canais de língua estrangeira, como TED Talks e PBS, por exemplo.

Acerca dos quatro canais mais citados, é possível observar a relevância destes quanto ao grande número de inscritos e de acessos, o que indica uma alta audiência nesses canais. Silva, Pereira e Arroio (2017) apontam que os canais Descomplica e Biologia Total com o Prof. Jubilut são os canais mais assistidos pelos estudantes. Medina, Braga e Rego (2015) relataram que os canais mais acessados pelos estudantes para buscar conteúdos de Ciências ficaram entre Biologia Total com o Prof. Jubilut, Me Salva e Descomplica. Nesse sentido, é nítido o destaque desses canais em diferentes contextos de pesquisa, o que mostra sua influência dentro do YouTube e com os estudantes.

É interessante ressaltar que, dentre os mais citados, os canais do Biologia Total com o Prof. Jubilut e Prof. Kennedy Ramos são iniciativas individuais voltadas unicamente aos conteúdos de Biologia, ao passo que os canais Descomplica e Me Salva, que possuem maiores números de visualizações e de vídeos e são construídos por um grupo de pessoas de diversas áreas do conhecimento, produzem vídeos sobre diferentes disciplinas. Assim, segundo a classificação de Medina, Braga e Rego (2015), seriam canais preparatórios, enquanto que os canais de uma disciplina específica seriam chamados de especializados.

Por conseguinte, os quatro canais declaram-se voltados ao ensino médio, com foco nas provas de larga escala, como ENEM e também vestibulares, afirmando-se como facilitadores do processo de entrada na universidade e preparatórios para a realização de uma boa prova. Afirma a descrição do canal Me Salva em seu website:

[...] se preparar para uma prova, que pode ser da escola, ENEM, vestibular ou disciplinas da Universidade; estudar em seu próprio ritmo; treinar os conteúdos aprendidos através de exercícios com resolução em texto, simulados e provas de edições anteriores do ENEM e vestibulares. (ME SALVA, 2018).

Com isso, fica claro que a produção desses canais é voltada para o contexto do estudante vestibulando ou em situação de prova, que muito provavelmente estará cursando o ensino médio. Ainda, esses canais vêm se abrindo também para o nicho universitário, tentando acolher demandas de estudantes graduandos. E assim, com objetivos principais como o alcance de boas notas nas provas, os estudantes de ensino médio buscam esses canais para estudar para as provas, logo, vê-se uma relação estreita entre oferta e demanda.

Os quatro canais mais citados, além dos vídeos públicos disponibilizados no YouTube, vendem pacotes de materiais diversos, possuindo opções de estudo que vão desde o ensino

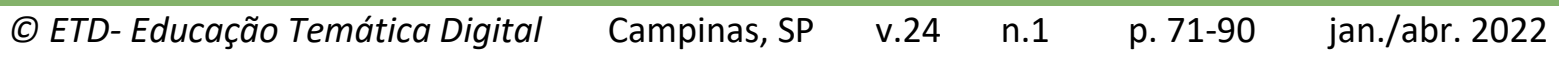


médio até a pós-graduação, apresentando valores muito inferiores quando comparados com cursinhos pré-vestibulares particulares presenciais. Segundo os estudantes:
M: Até onde eu saiba, o descomplica, ele tinha uma parte que era liberada grátis e tinha uma parte que é privada, não é?

\section{E4: É isso aí!}
E1: Tem alguns vídeos deles que não são completos, que "tu pega", tipo, só o comecinho porque o resto é [...].
E4: A maioria, tipo, a maioria dos canais do Youtube faz isso, sabe, eles, tipo, se tu precisar de qualquer conteúdo, sei lá, de Biologia mesmo, o começo do conteúdo tá lá, só que a parte mais aprofundada não tá, que é o que eles te vendem, sabe?
$\mathrm{M}$ : E alguém sabe o valor? Alguém comprou?
E3: Eu pago o descomplica, pago 20 [reais] por mês.

Vê-se que o acesso completo ao conteúdo dos vídeos muitas vezes é restrito a assinantes e que os estudantes consomem esses pacotes para além dos vídeos gratuitos disponibilizados no YouTube, como garantia de um acesso mais amplo. Assim, esses canais, além de assumirem um trabalho com os conteúdos de Biologia voltados à resolução de provas, oferecem pacotes privados de conteúdos para serem pagos mensalmente, e assim, garantem um estudo mais divertido e "certeiro" para a aprovação, para conquistar os clientes.

Por conseguinte, quanto à grande quantidade de abstenções, estudantes que não se lembram ou que não têm especificidade na escolha do canal apresentaram números significativos, o que pode ser justificado pelo fato de que os estudantes não costumam pesquisar os canais pelos nomes, e sim pelo conteúdo a ser estudado, acabando por "cair" nesses canais mais famosos, sendo os quatro já citados anteriormente. Afirma o E3: "Foi o primeiro que apareceu na busca". O E5 completa: "Exatamente, a primeira opção". Assim, reforça o fato que não necessariamente há uma escolha por parte dos estudantes, relacionada ao nome do canal, acabam por ficar entre os primeiros ofertados.

Ainda, os estudantes associam a escolha do que vão assistir com a estética do vídeo apresentado na página de busca. Afirma o E3: "Pô, o do Kennedy foi o primeiro que apareceu 'pra mim', tem a cara dele, tipo assim [fazendo mímica] na tela, achei chamativo"; completou o E4: "Então, é tipo os primeiros, e entre os primeiros, os que são mais bonitinhos". Com isso, notou-se que a aparência visual é um grande influenciador na escolha dos vídeos de Biologia que vão assistir no YouTube. Os jovens são cativados pelas cores e outras impressões estéticas.

Assim, os quatro canais mais indicados pelos estudantes apresentam um modelo semelhante entre si. Como visto em Medina, Braga e Rego (2015), são aulas-show, coloridas

(C) ETD- Educação Temática Digital Campinas, SP $\quad$ v.24 $\quad$ n.1 $\quad$ p. 71-90 jan./abr. 2022


e chamativas, animadas, e com métodos mnemônicos. Segundo Rezende Filho et al. (2015), esses canais apresentam um modelo tradicional, que reforça um sistema de educação vigente e que tem o aluno como espectador e reprodutor de informações e o professor como o sujeito ativo do processo. Esse modelo objetiva a transmissão de conhecimentos a fim de que os estudantes tenham um bom desempenho nos testes que virão a fazer.

Já canais de vídeo que tratam de Biologia de uma maneira mais transversalizada, uma abordagem enriquecida com outras disciplinas, que não têm a transmissão de conteúdos como objetivo final, como Canal do Pirula, Nerdologia e Canal do Slow, são menos vistos do que os anteriormente citados e, por vezes, nem reconhecidos pelos estudantes como aulas em vídeo sendo notória a preferência dos estudantes por canais mais tradicionais (MEDINA; BRAGA; REGO, 2015).

Em síntese, os estudantes buscam os conteúdos tanto em canais exclusivos quanto em canais preparatórios. Por acreditarem no retorno que esses vídeos possuem com o sucesso nas avaliações, alguns estudantes vão além nessa ferramenta e pagam para terem acesso ilimitado aos conteúdos. Outro ponto relevante é que existe um grupo de canais mais populares que outros e que são escolhidos especialmente pelo modelo estético que apresentam: coloridos e chamativos. Assim, os vídeos que apresentam uma concepção tradicional de ensino voltado às provas são mais buscados em detrimento de vídeos que abrangem conteúdos transversais.

\subsection{Vídeos no YouTube: limites e potencialidades}

Os vídeos do YouTube, como ferramentas de múltiplas possibilidades, exercem um papel significativo no processo educativo dos jovens estudantes do ensino médio, atuando de alguma forma na formação desses jovens (SILVA; PEREIRA; ARROIO, 2017). Durante o grupo focal, os estudantes, no geral, afirmaram que os vídeos no YouTube apresentam-se como boa fonte de informação, que interage e os mantêm descontraídos, também, que os vídeos constantemente trazem informações novas e diferentes do que viram em sala de aula, além de elementos que facilitam o estudo e a aprendizagem para a prova, bem como apresentam uma qualidade de produção muito boa. Segundo Silva, Pereira e Arroio (2017), dentre as facilidades que os vídeos apresentam, está o ambiente perfeitamente adequado a isso, com todos os aparatos e equipamentos necessários, o que, infelizmente, não é a realidade de muitas salas de aula brasileiras.

Assim, a partir do uso do YouTube para acessarem conteúdos curriculares, os jovens ampliam a forma e a linguagem com que aprendem, dado que os vídeos apresentam uma linguagem do seu cotidiano bem como aumentam a motivação e atenção ao inserirem elementos da cultura jovem, como piadas, palavrões e brincadeiras de duplo sentido (SILVA;

$\begin{array}{llllll}\text { (C) ETD-Educação Temática Digital } & \text { Campinas, SP } & \text { v.24 } & \text { n.1 } & \text { p. 71-90 } & \text { jan./abr. } 2022\end{array}$


SALES, 2015; MEDINA; BRAGA; REGO, 2015), mostrando-se, assim, mais interessantes, significativos, lúdicos.

Ainda, a impessoalidade mostrou-se como uma questão um pouco controversa no discurso dos estudantes. Valorizaram-na quando se afirmam desconfortáveis para fazer perguntas ao professor em sala, por vergonha ou medo de repreensão, e quando buscam os vídeos ou fazem comentários neles, a fim de sanar dúvidas, não se sentem julgados nem pressionados. Afirma E4:

[...] Então a relação com o vídeo é que em nenhum momento o vídeo vai te julgar, sabe? [...] Então, tipo, querendo ou não, é um método mais impessoal e por isso ele é útil, porque eu posso, tipo, trocar de vídeo se eu não gostar de quem tá na tela, mas eu não posso trocar de professor.

Assim, pode-se perceber a impessoalidade do vídeo sendo vista como positiva na fala de E4, dado que permite aos estudantes tirarem dúvidas sem se preocuparem com o julgamento ou com a vergonha. Em adição a isso, Silva, Pereira e Arroio (2017) viram, nos relatos dos estudantes, que eles sentem que, em sala de aula, o professor não tem mais paciência de responder. Assim, não raro, preferem assistir novamente ao vídeo a lidar com a indisponibilidade ou questões de afinidade com o docente.

Entretanto, em outros momentos, os estudantes apresentaram a questão da impessoalidade como negativa, valorizando o papel da escola, do professor e das relações entre os sujeitos. Quando questionados sobre preferir aulas em sala ou em vídeo, os estudantes entraram em conflito, mas a maioria afirmou preferir aulas em sala, e continuaram a discussão: 
E1: Vídeo você pode voltar e tal, ver de novo, na sala, não é bem assim.

E5: Ah, mas o professor pode explicar de novo!

E8: $E$.

E7: É.

E1: Depende.

E8: Sim, se "tu quiser" voltar, pede pro professor repetir.

E5: Mas assim ó. E1 pensa aqui o exemplo, se "tu não entendeu" o que tá no vídeo, tu voltar vai continuar sem entender.

E3: Ou "tu vai" pra outro, né? Tem essa possibilidade.

E1: É.

E7: Mas aí "tu não pode" tirar dúvida.

Assim, mesmo os estudantes afirmando as aulas em vídeo como interativas, práticas e divertidas, podendo assistir quantas vezes quiserem, parece reconhecerem algumas limitações, visto que, aparentemente, o YouTube não supre a demanda de relações interpessoais presenciais, como a facilidade de tirar uma dúvida, por exemplo. Assim, essas interações que acontecem em sala de aula ultrapassam a construção do conhecimento em si e fortalecem o fator humano e a estrutura social (SILVA; PEREIRA; ARROIO, 2017). Logo, os estudantes valorizaram as relações interpessoais e de aprendizagem com colegas e professores, bem como a dinâmica de sala de aula. Afirma o E8: "Tu em sala de aula, tu pode fazer pergunta, [...] tu pode expandir teus pensamentos junto com o professor, na vídeo-aula não, é só aquilo que tu tá vendo [...]".

Nesse contexto, ainda que com limitações, os estudantes afirmaram acreditar nos vídeos como uma boa ferramenta de aprendizagem de conteúdos curriculares. Quando questionados sobre o porquê, trouxeram elementos como: esquemas, macetes e simplificações que auxiliam com que memorizem o conteúdo mais facilmente para realizar uma avaliação, afirmou o E1: "Dependendo da metodologia do professor, tu acaba gravando mais fácil, de quem tá explicando, eles fazem esqueminha no quadro, que nem no Me Salva, que, pelo menos pra mim, é mais fácil, uma coisa mais visual de gravar [...]".

Nesse sentido, parece haver uma concepção de aprendizagem mnemônica por parte dos estudantes, pautada numa perspectiva de facilidade e de agilidade. Afirmaram na conversa: 
M: Então vocês preferem saber a fórmula e o que vai ser necessário para vocês, do que saber a coisa "tim tim por tim tim"?

E8: Eu acho que não.

E5: Depende da matéria.

E3: Depende.

E8: Assim, é melhor pra ti saber da onde partiu, como é que surgiu e tudo mais, mas daí na hora de aplicar, é bem mais fácil tu saber já de cara sabe, do que ficar pensando, ai, nossa como é que era aquilo mesmo, sabe?

E5: Perder uma aula pensando

E8: É, então, daí tu pode começar vendo aquilo por inteiro e depois ir praticando só com aquilo que "tu realmente" vai precisar.

No relato, vê-se que os estudantes demonstram consciência de que entender integralmente os processos e os conteúdos é importante, porém, sabem que, em muitas avaliações, isso não será tão relevante. Então, focam em estudar apenas o necessário, não indo além no seu processo de estudo e aprendizagem. Assim, acabam por reforçar um modelo conservador de ensino e aprendizagem quando buscam os vídeos no YouTube para memorizar conteúdos tanto quanto possível para tirar boas notas em exames. Parece assim que os estudantes se utilizam de uma inovação tecnológica para a busca de uma aula que não apresenta nenhuma inovação didática (MEDINA; BRAGA; REGO, 2015).

Um último ponto foi que os estudantes não costumam usar os vídeos do YouTube para aprender conteúdos "do zero" (MEDINA; BRAGA; REGO, 2015; SILVA; PEREIRA; ARROIO, 2017). Veem as aulas em vídeo como ferramentas complementares ao conteúdo ensinado em sala de aula, assim como afirma o E1: "É uma ferramenta a mais 'pra' te ajudar a complementar o que tu escutou na sala". Então, os conteúdos que são trabalhados em sala servem de base e pré-requisitos para que entendam o que está sendo tratado no vídeo, pois buscam nele um ponto de referência que faça a conexão com o que já foi visto em sala.

\section{CONSIDERAÇÕES FINAIS}

Dados os resultados apresentados, pode-se perceber que a maioria dos estudantes do ensino médio, já ligados às tecnologias, faz uso frequente do YouTube para acessar conteúdos de interesse pessoal, bem como conteúdos curriculares de Biologia, sendo as provas escolares a maior motivação para buscarem esse segundo. Também, vestibulares e provas de larga escala influenciam nessa busca ao ponto de os estudantes pagarem pelos cursos preparatórios extras ofertados por alguns canais. 
Os quatro canais mais citados pelos estudantes participantes destacaram-se pela alta popularidade e produções técnicas de alta qualidade. Ainda, apresentam um modelo tradicional no sentido em que ensinam com objetivo de que os estudantes reproduzam o conteúdo e tirem boas notas em exames, o que agrada ao público mas reproduz um modelo escolar conservador de professor ativo transmissor e estudante passivo receptor.

Por conseguinte, como o YouTube já faz parte da busca autônoma de informações por parte dos estudantes, é importante um olhar crítico perante esse conteúdo. Nesse viés, os resultados aqui apresentados fazem refletir, principalmente, sobre a forma como está posta a avaliação escolar e o peso que ela tem, em formato de prova, na vida dos estudantes, impedindo-os de expandir para outras formas de aprender mais críticas e menos fragmentadas. Além disso, é importante que mais olhares se voltem para esses outros ambientes e linguagens de aprendizagem que vêm sendo tão requisitados pelos estudantes, como as videoaulas do YouTube, especialmente no que tange às concepções didático-pedagógicas desses materiais.

Por fim, estudos como este apresentam-se dentro de uma temática atual e relevante que está longe de ser esgotada, sobretudo, a partir do movimento polêmico de estímulo ao ensino remoto que se tem vivenciado. Logo, buscamos com essa e outras pesquisas já em andamento, o aprofundamento de reflexões sobre os vídeos educativos do YouTube e seus impactos no processo de ensino e aprendizagem em Biologia.

\section{REFERÊNCIAS}

ASLAM, S. YouTube by the Numbers: Stats, Demographics \& Fun Facts. Disponível em: https://www.omnicoreagency.com/youtube-statistics/Acesso em: 15 novembro 2021.

MELO, M. E. Investigando o uso de vídeos de biologia no YouTube por estudantes do ensino médio. 2018. Trabalho de Conclusão de Curso (Graduação em Licenciatura em Ciências Biológicas), Universidade Federal de Santa Catarina, Florianópolis, 2018.

BÉVORT, Evelyne; BELLONI, Maria Luiza. Mídia-educação: conceitos, história e perspectivas. Revista Educação e Sociedade, São Paulo, v. 30, n. 109, p. 1081-1102, set./dez. 2009.

COLÉGIO DE APLICAÇÃO DA UNIVERSIDADE FEDERAL DE SANTA CATARINA (CA-UFSC). Projeto Político Pedagógico: versão resumida. Florianópolis: CA-UFSC, 2012. Disponível em: https://moodle.ufsc.br/pluginfile.php/2451122/mod resource/content/2/PPP-revisadoCA.pdf. Acesso em: 02 nov. 2018 
CABRAL, Luciana. Ferrari. Espíndola.; REZENDE FILHO, Luiz. Augusto. Coimbra.; SANTOS, Gisele. Abreu. Lira. Corrêa. Práticas e discursos neoliberais na inserção do audiovisual no ensino de ciências em canais de ciências no YouTube. In: ENCONTRO NACIONAL DE PESQUISA EM EDUCAÇÃO EM CIÊNCIAS, 12., 2019, Natal. Anais [...]. Natal: ABRAPEC, 2019. p. 1-11.

DUARTE, Manoelle Silveira. A contribuição dos recursos das TDICs no processo de ensinar e aprender. 2016. Dissertação (Mestrado em Educação) - Programa de Pós-Graduação em Educação, Universidade Regional Integrada do Alto Uruguai e das Missões, Frederico Westphalen, 2016.

FERRÉS, Joan. Vídeo e Educação. 2. ed. Porto Alegre: Editora Artes Médicas, 1996.

GATTI, Bernadete Angelina. Grupo focal na pesquisa em ciências sociais e humanas. Brasília: Liber Livro, 2005.

GIL, Antonio Carlos. Questionário. In: GIL, Antonio Carlos. Métodos e técnicas de pesquisa social. 6. ed. São Paulo: Atlas, 2008. p. 121-135.

ME SALVA. Cursinho online e aulas de reforço. 2018. Disponível em: https://www.mesalva.com/. Acesso em: 08 nov. 2018.

MEDINA, Márcio Nasser; BRAGA, Marco; REGO, Sheila Cristina. Ensinar ciências para alunos do século XXI: o uso de vídeo-aulas de ciências da natureza por alunos do ensino médio de uma escola pública federal. In: ENCONTRO NACIONAL DE PESQUISA EM EDUCAÇÃO EM CIÊNCIAS, 10., 2015, Águas de Lindóia. Anais [...]. Águas de Lindóia: ABRAPEC, 2015.

MINAYO, Maria Cecília de Souza et al. Pesquisa social: teoria, método e criatividade. 21. ed. Rio de Janeiro: Editora Vozes, 2002.

PASTOR JUNIOR, Américo de Araujo et al. Os usos de filmes, séries de TV e vídeos do YouTube por estudantes e professores nas aulas de Psicologia Médica. In: ENCONTRO NACIONAL DE PESQUISA EM EDUCAÇÃO EM CIÊNCIAS, 11., 2015, Florianópolis. Anais [...]. Florianópolis: ABRAPEC, 2017.

REZENDE FILHO, Luiz Augusto de Coimbra et al. Canais de vídeo para ensino de ciências: um estudo exploratório. In: ENCONTRO NACIONAL DE PESQUISA EM EDUCAÇÃO EM CIÊNCIAS, 10., 2015, Águas de Lindóia. Anais [...]. Águas de Lindóia: ABRAPEC, 2015.

SILVA, Marcelo José; PEREIRA, Marcus Vinícius; ARROIO, Aguinaldo. O papel do YouTube no ensino de ciências para estudantes do ensino médio. Revista de Educação, Ciências e Matemática, São Paulo, v. 7, n. 2, p. 35-55, maio/ago. 2017. 
SILVA, Marco Polo Oliveira; SALES, Shirlei Rezende. O fenômeno cultural do YouTube no percurso educacional da juventude ciborgue. In: SEMINÁRIO BRASILEIRO DE ESTUDOS CULTURAIS E EDUCAÇÃO, 6., e SEMINÁRIO INTERNACIONAL DE ESTUDOS CULTURAIS E EDUCAÇÃO, 3., 2015, Canoas. Anais [...]. Canoas: SBECE, 2015.

VIDAL, Fernanda Luise Kistler; REZENDE FILHO, Luiz Augusto de Coimbra. Utilização de recursos audiovisuais (RAVS) na educação em ciências: uma análise dos trabalhos publicados nos I, II e III EREBIO (SE) e I ENEBIO. In: ENCONTRO NACIONAL DE PESQUISA EM EDUCAÇÃO EM CIÊNCIAS, 7., 2009, Florianópolis. Anais [...]. Florianópolis: ABRAPEC, 2009.

YOUTUBE. Youtube para a Imprensa. Brasil. Disponível em: https://blog.youtube/press/ . Acesso em: 15 novembro 2021.

Revisão gramatical realizada por: Aline Knorst Tavares

E-mail: amatextos@gmail.com 